\title{
The Relationship between Achievement Motivation and Academic Achievement among the Students of Physical Education Faculty in El-Arish
}

Dr/ Ebtessam Abdel Kader Abdel Aziz

\section{Introduction:}

Demonstrating the motivating forces that show the learner's behavior and direct it is a critical matter to the process of teaching and learning. Motivation is a prerequisite upon which the achievement of educational goals depends in the areas of multiple education, either in the collection of information and knowledge (cognitive aspect), the configuration of attitudes and values (sentimental aspect), or the configuration of different skills that are subject to training and practice factors (kinetic aspect). (19)

Motivation is one of the controversial concepts in the field of psychology. It is defined as "a state of tension that stimulates the behavior in certain circumstances and directs and affects it. In other words, it is "the state of a special interaction that orients the individual's behavior. (15)

Khairallah defines motivation as latent energy in the organism, which stimulates him to exhibit a certain behavior in the outside world. This is done by selecting a functionally useful response in the adaptation process with the external environment. (8)

Motivations have three basic functions in behavior; move, activate, direct and maintain its sustainability until needs are satisfied and balance is regained. (16)

The achievement motivation is one of very important aspects of humanitarian motivation system. It is a fundamental component in the process of individual's realization, behavior guidance, and selfactualization through goals achievement. Scientists and researchers, such as McClelland, indicate that the achievement motivation is a default configuration that means the feeling of evaluative performance, where there is a competition to achieve the excellence standards. It is also that feeling of failure, through the individual's endeavors to 
exert maximum effort and struggle for success and achieve the best and superiority over others. (21)

Atkinson also confirms that the individual's expectation for his performance, self-awareness of his ability and its consequences are ranked as mutual cognitive relations that lie behind the achievement behavior. $\mathrm{He}$ indicates that individuals with high achievement motivation exert a great effort in the fields of access to problem-solving. (4)

Ball adds that high achievement motivation increases the individuals' ability to adjust themselves in work to resolve the problem, and it enables them to elaborate plans to satisfactorily follow up to gain access to the solution. (6)

Ragaa Mahmoud abou Allam defines the achievement motivation as "internal state linked to the individual's feelings and directs his activity towards the planning and implementation of this work plan in order to achieve a certain level of excellence in which he believes. (1)

Nabil Mahmoud Alfahel is consistent with this hypothesis. He adds to the excellence and superiority the distinctive personality of the individuals who are characterized by a high level of achievement motivation. The nature of these individuals is to pursuit in the direction of access to a high level of excellence. This trend is a key component and desire in the achievement motivation, which represent a personality characteristic of the individuals with a high level of motivation. (2)

\section{Research Problem}

Achievement and learning motivation is a state of general motivation. It refers to the learner internal state, which stimulates him to pay attention to the educational situation, actively prompt it, and continue until achieving learning. (24)

Achievement motivation force contributes to maintain high performance levels of students without special monitoring. This is demonstrated through the positive relationship between achievement motivation and perseverance in work and good performance. Thus, motivation achievement is a good way to predict academic behavior 
associated with success or failure in the future. (18)

Individuals who have a high level of academic achievement motivation are characterized by greater seriousness in work than others are, and achieve more successes in their lives and in various life situations. When comparing these individuals by those who have low achievement motivation, it is indicated that the first group achieves more progress and has much more ambition than their ability to achieve it. (17)

The study of achievement motivation in the education is of the key concepts of focus. Many studies indicate the role of achievement motivation in the educational process, and the factors and variables affected by and have an effect on it. Achievement is the motivation that directs the individual to academic achievement. This motivation is linked to certain criteria developed by the community to indicate the privilege fields of behavior. Individuals are varied in the strength and weakness of this motivation. Some work hard, and others do not even make an effort with their abilities. Training on independence develops self-reliance and achievement motivation at the same time. However, training strength on the achievement may strengthen independence motivation; it does not necessarily lead to strengthen achievement motivation. (15)

Stimulating students' motivation, directing it, and generating interests make them tend to practice of a variety of educational activities with high performance, which adopt effective ways in data processing that the student deals with during the achievement process. Jehan Abu Rashid indicates to motivation and its relationship to academic achievement, using motivation test. Its results confirm that there is a relationship between these two variables (14)

A study conducted by Mohamed Radwan refers to a comparison between those who have a high level of achievement and a low level of achievement, using achievement motivation scale. The results indicate that there are differences in favor of those with high achievement, where they were more motivated. (11) 
Osama Rateb suggested that people with high degree of achievement have general characteristics; they are realistic and show a bit perseverance in their performance and work at a high rate performance. (15)

The researcher believes that academic achievement is a standard to which the students' educational level can be determine. It depends primarily on the student's ability, his experience, skill and training. However, student may be affected by certain factors, including motivation. There are also many factors that interfere in the achievement process linked to the student such as his mental ability and others linked to the educated experience and the way to learn or environmental conditions that surround the student, including family and community.

Therefore,

the importance of achievement motivation, its influence on the achievement process, and interactive effect between both of them, and through the work of the researcher, she discovered that it is important to study the relationship between achievement motivation and academic achievement and linked them to gender variable among the students of the Faculty of Physical education in El-Arish.

\section{Research Significance}

Theoretically:

Achievement Motivation

plays an important role in developing the individual level performance in various fields. This was confirmed by McClelland that achievement motivation level found in any community is the result of the way in which children are grown up in this society. (21) Thus, the importance of achievement motivation is not only for academic achievement but also for the community where they live. The study of achievement motivation constitutes among students great importance as the motivation availability stimulates students' activity and enthusiasm for learning, and thus their achievement. It also helps teachers to understand and interpret the performance of students in different learning situations. The study of motivation helps the teacher to take advantage of the maximum capacity of students to achieve the required academic 
Therefore, students' perceive to learning changes, its importance increases and helps in the preparation of specialized generation whose chances of its contribution increase to the planning and implementation of learning and success.

\section{Practically:}

The study of achievement motivation variable alerts the staffs who work in the psychological educational field to be ready for the planning of their teaching and to develop strategies for increasing the achievement motivation to ensure high academic achievement. This also would enable them to suggest some ideas that contribute to clarify how to deal with the students to intervene in the factors affecting their motivation and thus increase the level of achievement.

\section{Objectives}

This research aims to identify the relationship between achievement motivation and academic achievement among the second division students of the Faculty of Physical Education in ElArish.

\section{Research Queries}

1. What is the relationship between motivation and academic achievement among the research sample (male and female students of the Faculty of Physical Education in ElArish)

2. What are the differences in achievement motivation among the male and female students of Physical Education Faculty in El-Arish

3. What are the differences in academic achievement among the students of Physical Education Faculty in El-Arish. Research Terms

Achievement Motivation: McClelland defines achievement motivation that performance in light of a certain level of excellence and superiority. (21)

Academic achievement: the grades average obtained by a male or female student in one of academic subjects or group of academic subjects.

\section{Previous Studies}

\section{Arabic Studies}

Al-Nahel (2000) conducted a study of "self-esteem and achievement motivation among secondary school students in both Egypt and Saudi Arabia, cultural study". The sample included 120 students; 60 of them were Egyptian students with an average age of 16 years, and 60 Saudi students with an average age of 18 years. The study indicated that there is a strong correlation between student's confidence 
in himself and his/her desire to achieve excellence in both Saudi Arabia and other Arab Students. (2)

Mustafa

conducted a study on "school motivation among the students of Faculty of Education in ElArish, according to the variables of gender, major, and academic level." The study sample included two different groups of students. The first group consisted of 40 students from the science section and 37 students from the first-year of the literary section. The average age of those students is 17 years. The second group included 32 male students and 22 female students; 26 male students were from the scientific section and 26 female students from the literary section in the 4th year. The average age of the second group was 21 years. The study tools were represented in a test measuring the motivation. The study concluded that there were statistically significant differences between the scores of the first-year scientific students and the 4th yearstudent in the positive motivation and negative motivation of learning in favor of female students. There were differences between first-year scientific students and their colleagues in the fourth year. There were not significant differences between the two average scores of both groups of 4th-year scientific students and 4th-year literary female students.

Rashid (1994) conducted a study on "achievement motivation and its relationship to academic achievement and some demographic variables among a sample of primary and preparatory students in Bahrain." The study aimed to identify the relationship between achievement motivation and academic achievement. It also aimed to identify the impact of differences between children who belong to different geographical areas in achievement motivation, as well as the relationship between family size and achievement motivation. The study sample included 377 male and female students randomly selected from eight male and female primary and preparatory schools in Bahrain. The researcher used the achievement motivation in measuring the students' 
motivation for achievement. (14)

$$
\text { El-Sayed (1992) studied }
$$

the targets of "achievement in the classroom and their relationship to causal attribution to academic achievement" among a sample of first-year secondary students in Sharkia, Egypt, in the framework of goals theory. The researcher concluded that there is a positive statistically significant correlation between avoiding work and ability. The relationship between goals of achievement motivation and attribution and the failure of achievement. The study indicated that there is a statistically significant negative relationship between performance and task and there is a positive statistically significant relationship between avoiding work and task.

Khamis

conducted a study on "the impact of achievement motivation and intelligence on the ability to solve problems among 7th, 8th, and 9th grades students in Amman" through a sample of 650 male and female students. Group test of intelligence, achievement motivation scale built by Smith
(1973), and the ability to solve a problem were all applied to them. The results indicated that there was statistical significance for achievement motivation and intelligence in the ability to solve the problem, while there was no statistical significance of the level of interaction between the two independent variables (achievement motivation and intelligence) and the dependent variable (the ability to solve problems). This demonstrated that individuals with high achievement motivation are characterized by more effectively in problem-solving and higher ability in the academic achievement and work on mental tasks requiring a high degree of mental effort and cognitive processes. This result is in line with McClelland and Atkinson concluded when they assumed that most of the human behavior patterns could be explained through one of the important components of the motivation, which is the need for achievement. This need gives the individual the desire to be successful in activities that reflect the standards of excellence, overcome obstacles and solve problems. (9) 
Radwan (1987) conducted a comparative study of the high and low achievers in achievement, using the achievement scale and concluded that there were statistically significant differences in favor of those with high achievement where they were more motivated.

Mussa (1987) conducted a study on two groups of students having equal ability and different in achievement motivation. The study indicated that students with high motivation achievement outperformed their peers in speed tests in language and math problem solving. (12)

\section{Foreign Studies}

Vermeer, Harriet J.; Boekaerts, Monique; Seegers, Gerard (2000) conducted a study concluded that the achievement motivation is positively associated with cognitive processing ability to solve problems and accomplish difficult tasks, which constitute a burden on the working memory. These studies also confirmed that the achievement motivation has its assets in learning experiences during childhood years. (23)

Tyler, Doris Kennedy; Vasu, Ellen Storey (1995) conducted a study aimed to investigate the relationship between the controlling center, self-esteem, achievement motivation, and problem-solving ability. The study sample included 63 male and female students from the 3 rd to 5th grade. Problemsolving ability test was applied. It included six strategies that consisted of the formation of sub-goal, series tie, series loose, alternative representation, and symmetry strategy. The results indicated that there was a strong and statistically significant correlation between achievement motivation and problem-solving ability. (22)

Siry, Joanne Michaele (1990) conducted a study aimed to verify the relationship between the levels of ambition in those with high and low achievement motivation and their ability to solve problems. It concluded that students with high level of ambition for achievement had high performance in solving problems, and with statistically significant difference from those with low ambition to achievement. It also indicated that the ambition level of the study members fluctuated during the work on solving problems, which increases after 
any successful performance and decreases after any unsuccessful performance. There were also statistically significant differences between males and females in the ambition level of achievement. (20)

Klinger, Eric (1966) conducted a study by which they sought to investigate the studies that examined the relationship between achievement motivation and academic achievement. They demonstrated that there are two studies of each five studies reviewed, which proved that students with high achievement motivation were higher than the others were with low motivation in achievement. (10)

\section{Research Procedures Methodology}

Descriptive approach with survey method is used due to suitability for the study nature.

Research Population

Research community is determined by 2nd-year student at Faculty of Physical Education in El-Arish (20142015). They are 200 male and female students.

Research Sample

A random sample of 150 male and female students was selected, which represents $75 \%$ of the research community. 50 male student and 50 female students were selected randomly from 2nd-year students of Faculty of Physical Education in El-Arish. Thus, the sample representation of the community is $50 \%$.

Exploratory Sample

The researcher selected an exploratory sample of 50 male and female students who represent $25 \%$ of the research community, which consists of 200 students.

\section{Data Collection Tools}

After reviewing the previous studies relevant to achievement motivation and academic achievement, the researcher discovered that it is better to use rated achievement motivation taken from AlKnani scale (1979), which was based on the responses of 300 male and female students to some questions. The number of scale paragraphs was 151 items designed to measure academic achievement motivation. After examining the scale, the researcher concluded a scale consisted of 52 paragraphs accompanied by five responses as the following: "I strongly agree; I agree, I do not know, I do not agree; I strongly 
disagree. The respondent is asked to mark one of them and a score is given for each response. The student response with Agree is estimated with five degrees when the statement reflects positive indicators to academic achievement

\section{Table (1)}

\begin{tabular}{l|c|c|c|c|c}
\hline \hline \multicolumn{1}{c|}{ Statement } & $\begin{array}{c}\text { I } \\
\text { strongly } \\
\text { agree }\end{array}$ & I agree & $\begin{array}{c}\text { I do } \\
\text { not } \\
\text { know }\end{array}$ & $\begin{array}{c}\text { I } \\
\text { disagree }\end{array}$ & $\begin{array}{c}\text { I } \\
\text { strongly } \\
\text { Disagree }\end{array}$ \\
\hline \hline $\begin{array}{l}\text { Statements reflect the } \\
\text { positive indicators of } \\
\text { achievement motivation }\end{array}$ & 5 & 4 & 3 & 2 & 1 \\
\hline $\begin{array}{l}\text { Statements reflect the } \\
\text { negative indicator of } \\
\text { achievement motivation }\end{array}$ & 1 & 2 & 3 & 4 & 5 \\
\hline \hline
\end{tabular}

The total score ranges for this scale after adding the degrees of its paragraphs between (52-260) degrees. The researcher then display the scale on a group of arbitrators. In light of this, the researcher excludes, according to observations of the arbitrators, six paragraphs of the scale due to their mismatching with undergraduate students and the characteristics of the research community represented in male and female students of Physical Education Faculty in El-Arish. The scale takes its final form on 46 paragraphs divided into (26) Positive, (20) Negative.

\section{Exploratory Study}

Scientific Parameters of Achievement Motivation

Scale:

Construct validity by using the internal consistency

The researcher has calculated construct validity by applying the test on a sample of 50 male and female students from the research community and outside the research sample. The correlation coefficients have been calculated between the degree of each statement and the scale total score. Table (2) illustrates this. 
Table (2)

Correlation coefficient between each paragraph or statement and the total score of achievement motivation scale

\begin{tabular}{c|c|c|c}
\hline \hline Statement No. & Correlation & Statement No. & Correlation \\
\hline \hline 1 & $0.32^{*}$ & 24 & $0.78^{* *}$ \\
\hline 2 & $0.31^{*}$ & 25 & $0.37^{*}$ \\
\hline 3 & $0.37^{*}$ & 26 & $0.67^{* *}$ \\
\hline 4 & $0.69^{* *}$ & 27 & $0.31^{*}$ \\
\hline 5 & $0.56^{* *}$ & 28 & $0.78^{* *}$ \\
\hline 6 & $0.56^{* *}$ & 29 & $0.30^{*}$ \\
\hline 7 & $0.78^{* *}$ & 30 & $0.28^{*}$ \\
\hline 8 & $0.78^{* *}$ & 31 & $0.31^{*}$ \\
\hline 9 & $0.37^{*}$ & 32 & $0.78^{* *}$ \\
\hline 10 & $0.61^{*}$ & 33 & $0.56^{* *}$ \\
\hline 11 & $0.78^{* *}$ & 34 & $0.30^{*}$ \\
\hline 12 & $0.35^{*}$ & 35 & $0.50^{* *}$ \\
\hline 13 & $0.78^{* *}$ & 36 & $0.78^{* *}$ \\
\hline 14 & $0.67^{* *}$ & 37 & $0.32^{*}$ \\
\hline 15 & $0.50^{* *}$ & 38 & $0.56^{* *}$ \\
\hline 16 & $0.35^{*}$ & 39 & $0.56^{* *}$ \\
\hline 17 & $0.78^{* *}$ & 40 & $0.78^{* *}$ \\
\hline 18 & $0.54^{* *}$ & 41 & $0.30^{*}$ \\
\hline 19 & $0.35^{*}$ & 42 & $0.30^{*}$ \\
\hline 20 & $0.78^{* *}$ & 43 & $0.78^{* *}$ \\
\hline 21 & $0.56^{* *}$ & 44 & $0.30^{*}$ \\
\hline 22 & $0.54^{* *}$ & 45 & $0.78^{* *}$ \\
\hline 23 & $0.29^{*}$ & 46 & $0.30^{*}$ \\
\hline \hline
\end{tabular}

Tabulated $(\mathrm{R})$ value $=$ at the significance level 0.05 .

Table (2) indicates that all correlation values between each statement and the scale as a whole are statistically significant at the significance level of 0.05 .
The reliability of achievement motivation scale

The researcher has calculated the reliability by applying the scale, re-applying it, and Cronbach's Alpha coefficient.

Table (3) illustrates this 
The above table indicates that there is a positive statistically significant correlation between achievement motivation and academic achievement among research sample.

\section{First Hypothesis Discussion:}

The researcher attributes the high achievement motivation among the research sample to the need for achievement that gives the individual a desire to be successful in the study that reflects the standards of excellence, overcomes the obstacles he faces, and higher ability to academic achievement.

A study consistent with the above results conducted by Ziad Khamis (1992) indicated that individuals with high achievement motivation are characterized by more effectiveness to solve problems and obstacles and have the ability of high academic achievement. (9)

A study conducted by Siry, Joanne Michaele (1990) indicated that achievement motivation positively associated with the ability to cognitive processing, which is associated with academic achievement and difficult tasks achievement. (20)

The results of current research are also consistent with those concluded by Klinger, Eric (1966) which indicated that students with high achievement motivation had more academic achievement than others did. (10)

A study consistent with the current research results conducted by Mussa Farouk (1987) indicated that the group with high achievement motivation outperformed their peers in speed tests in language, math, and problem solving. This indicates that the academic achievement of the group characterized by high achievement motivation variable is high. (12)

Second Hypothesis Results

Presentation

Table (6)

The Significant differences between male and female students in achievement motivation scal e $\mathbf{n}=\mathbf{5 0}$

\begin{tabular}{c|c|c|c|c|c|c}
\hline \hline \multirow{2}{*}{ Variable } & \multicolumn{2}{|c|}{ Male students } & \multicolumn{2}{|c|}{$\begin{array}{c}\text { Female } \\
\text { students }\end{array}$} & $\begin{array}{c}\text { The difference } \\
\text { between both } \\
\text { means }\end{array}$ & $\begin{array}{c}\text { (t) } \\
\text { value }\end{array}$ \\
\cline { 2 - 7 } & $\mathbf{A M}$ & $\mathbf{S}$ & $\mathbf{A M}$ & $\mathbf{S}$ & 10.14 & 3.07 \\
\hline \hline $\begin{array}{c}\text { Achievement } \\
\text { Motivation Scale }\end{array}$ & 137.60 & 18.03 & 147.80 & 14.78 & 14 \\
\hline \hline
\end{tabular}

Tabulated $(\mathrm{R})$ value $=(\ldots$.$) at the significance level of 0.05$. 
The above table demonstrates that the calculated $(\mathrm{t})$ value is greater than tabulated (t) value indicating that there are statistically significant differences in achievement motivation in favor of female students.

\section{Second Hypothesis}

\section{Discussion}

The existence of statistically significant differences in achievement motivation variable in favor of female students can be explained to the nature of Arab societies in recent time. Arab family turned to urge and encourage females just like male to achievement and working because they are half of the society and that this area is socially acceptable, and allows Arab women to superiority. Therefore, females have the desire to achieve superiority just like males.

The results of the second hypothesis are consistent with those of Mohamed Mustafa (1998) which indicates that there are statistically significant differences in the academic motivation. It was positive in favor of female students.

\section{Third Hypothesis Results Presentation}

Table (7)

The Significant differences between male and female students in academic achievement

\begin{tabular}{r|c|c|c|c|c|c}
\hline \hline \multirow{2}{*}{ Variable } & \multicolumn{2}{|c|}{ Male Students } & \multicolumn{2}{|c|}{ Female Students } & \multirow{2}{*}{$\begin{array}{c}\text { The difference } \\
\text { between both means }\end{array}$} & \multirow{2}{*}{$(\mathrm{t})$ value } \\
\cline { 2 - 5 } & $\mathrm{AM}$ & $\mathrm{S}$ & $\mathrm{AM}$ & $\mathrm{S}$ & \multirow{2}{*}{61.28} & 1.37 \\
\hline $\begin{array}{c}\text { Academic } \\
\text { achievement }\end{array}$ & 1378.18 & 227.15 & 1439.46 & 221.2 & \\
\hline \hline
\end{tabular}

Tabulated $(\mathrm{R})$ value $=(\ldots$.$) at the significance level of 0.05$

The above table demonstrates that the calculated $(\mathrm{t})$ value is greater than tabulated $(\mathrm{t})$ value indicating that there are statistically significant differences in academic achievement in favor of female students.

\section{Third Hypothesis Discussion}

The researcher attributes the existence of statistically significant differences in academic achievement in favor of female students. This emphasizes the second hypothesis, indicating that there are statistically significant differences in achievement motivation among female

This in turn led to increase academic achievement 
among them. The Arab societies encourage females now to prove themselves by allowing them to work and achieve. They are stimulated by their desire for occupying advanced position through outstanding performance and committed at the same time to traditions and customs. They also use their academic success in completing their role as influential members of family and achieve goals in well educating young generations. Arab woman now challenges her capabilities, prepares herself for success and commits herself with tasks from which she tries to achieve certain success.

The researcher believes that the Arab girl now has the ability to choose a more realistic work and to bring about compatibility between the capabilities and functions of her choice, and foresights expected results and how much time and effort required.

\section{References}

1- Abou Allam, Ragaa Mahmoud (2001). Research Methodology in Psychological and Educational Sciences. $3^{\text {rd }}$ Ed., Dar lil-Nashr lil-Gamaat, Qatar, pp: 297.
2- Al-Nahel, Nabil Mahmoud (2000). The study of selfesteem and achievement motivation among secondary school students in both Egypt and Saudi Arabia, a cultural study). General Egyptian Book Organization, Cairo, pp: 63.

3- Al-Tawab, Sayed Mahmoud (1990). The effect of the level of achievement motivation, intelligence and gender on academic achievement among students in the United Arab Emirates University. Journal of the Faculty of Education.

4- Atkinson, John W (1964). An introduction to motivation. Princeton, N.J., Van Nostrand, pp: 101.

5- Atwa, Atwa Al-Metwali (2014). Sports Psychology.

6- Ball, Sammel (1977). Motivation in Education. New York Academic Press, pp: 23.

7- Hamed, Mohamed bin Moagab (1995). The Factors affecting achievement motivation. Journal of Imam Muhammad ibn Saud Islamic University.

\section{8- Khairallah, Sayed} Mohammad (1973). Educational Psychology (theoretical and experimental foundations) Alam Al-Kotob, pp: 133. 
9- Khamis, Ziad (1992). The impact of achievement motivation and intelligence on problem solving capacity among 7th, 8th and 9th grade students in Amman. Unpublished Master Thesis. University of Jordan, Amman

\section{0- Klinger, Eric (1966)}

Fantasy need achievement as a motivational construct. Psychological Bulletin, Vol 66(4), Oct, 291-308.

\section{1- Maliki, Abdul Latif} (2007). Adolescent is an identity crisis or a civilization crisis. All Prints Distributors \& Publishers, Lebanon, 7th edition, pp: 70.

12- Mussa, Farouk (1987). Instructions Brochure of achievement motivation test for adult children. Nahdet Misr Library, Cairo, Egypt.

\section{3- Qatami, Nayef (1994).}

The impact of gender, adjustment site, and academic achievement level on achievement motivation among secondary school students. Dirasat Journal.

14- Rashid, Jehan Abu (1995). Achievement

Motivation and Its

Relationship to Academic Achievement and Some Demographic Variables among a Sample of Primary and
Preparatory Students in Bahrain. Dirasat Journal, pp: 56.

15- Rateb, Osama Kamel (1990). Excellence Motivations in Aports Activity (coach, player, educator). Dar Al Fikr El Arabi, Cairo, pp: 16, 130140, 45.

16- Riad Anwar \& Abdullah Shehoumi, (2006). Psychology of Teaching and Learning. Alahlia for Publishing and Distribution, Kuwait, pp: 47.

17- Santrock, John W, (2003). Psychology. McGrawHill, pp: 87.

18- Shafik, Alawneh (2004). Motivation, General Psychology. Edited by Mohammed Al-Rimawi, Dar Massira for Publishing and Distribution, Amman, pp: 70.

19- Shwashra, Atef Hassan (2007). The Effectiveness of an educational guidance program in stimulating achievement motivation for a student who suffers from low motivation in academic achievement (case study). Faculty of Educational Studies, Arab Open University, Jordan, pp: 2.

20- Siry, Joanne Michaele (1990). Level of Aspiration of High and Low Achievers on a Problem-Solving Task. The 
Psychological Record 40.2 Computing in Education, v28 (Spring): 197.

n1 p98-120 Fall

21- Suinn, R.M. (1980). Body

23- Vermeer, Harriet J.; thinking: Psychology for Olympic champs. In R. M. Suinn (Ed.), Psychology in Sports: Methods and applications. Minneapolis: Burgess. pp. 269.

22- Tyler, Doris Kennedy; Vasu, Ellen Storey (1995). Locus of Control, Self-Esteem, Achievement Motivation, and Problem-Solving Ability: LogoWriter and Simulations in the Fifth-Grade Classroom. Journal of Research on Boekaerts, Monique; Seegers, Gerard (2000). Motivational and gender differences: Sixthgrade students' mathematical problem-solving behavior. Journal of Educational Psychology, Vol 92(2), Jun, 308-315.

\section{4- Yusuf, Qatami \& Abdul Rahman, Adas (2002). General Psychology. Dar Al Fikr for Printing \& Publishing, Amman, pp: 60.}

